\title{
Study on the Influence of MOOC on Independent Colleges
}

\author{
Qinggong Ma \\ Huaide College \\ Changzhou University \\ Taizhou, Jiangsu, China, 214512 \\ e-mail: czjeepfans@163.com
}

\begin{abstract}
As a new way of teaching, MOOC quickly occupies the commanding heights of higher education by dint of its convenience, fastness and massive courses, and also provides a reference for other institutions of higher learning. In this paper, the influence of MOOC on independent colleges is rigorously expounded from four aspects of talent cultivation, teaching management, classroom teaching paradigm and individualized education so as to provide a new way of thinking for the development of independent college education and teaching.
\end{abstract}

Keywords-MOOC; independent college; individualized education; classroom teaching paradigm

\section{INTRODUCTION}

MOOC (Massive Open Online Course) is open online courses built on the basis of the Internet. Since the creation by Stanford University in the fall of 2011, it swept the world within a few years. In order to fully demonstrate and share teaching resources of universities, a considerable number of countries have joined the rank of the MOOC. MOOC curriculum not only covers math, engineering, science, computer science and other science and technology disciplines, but also covers the humanities and social sciences. With the continuous development of science and technology, information technology level has been greatly improved. Through a variety of mobile terminals, people will be able to quickly and easily access MOOC and acquire more knowledge. Although MOOC neither changes the teaching thought of colleges and universities nor has much theoretical innovation, this new way of knowledge dissemination has brought a considerable impact on the colleges and universities. As public private secondary schools, educational resources of independent colleges themselves lag behind those of regular higher educational institutions, belonging to vulnerable groups in higher education. Under the impact of this new teaching methodMOOC, their teaching and management is stretched and beset with difficulties. Unpredictable losses will be brought if the influence of MOOC is not carefully analyzed and relevant countermeasures are not taken.

\section{MOOC PROVIDES A GUIDELINE TTO THE INDEPENDENT COLLEGES FOR CULTIVATING INTER- DISCIPLINARY TALENTS}

As a content-rich new teaching approach, MOOC is based on modern information technology. Unlimited and diverse modern information technology methods and techniques bring a flood of information to the learners. In spite that only a very small part of the information may enter the classroom, the classroom is still greatly enriched after the information appears. The emergence of MOOC makes a lot of information flocking in the classroom and expands the teaching contents infinitely. To obtain the information unavailable from an ordinary classroom, learners will certainly choose MOOC which has a mass of information. Thus, by MOOC, learners can always easily obtain any information they can not get in other classes. In such a class, the traditional boundaries between disciplines are gradually blurred; professional attitudes are also more and more diluted; what have been learnt are not a single aspect but involving in multidisciplinary, multi-specialty comprehensive information. While talents cultivated through such way of learning are bound to be interdisciplinary, multi-disciplinary complex talents.

For the past several years, a considerable number of independent colleges have developed a variety of educational reforms in order to cultivate interdisciplinary, multidisciplinary complex talents and tried all kinds of cultivating modes, most of them return without accomplishing anything. Though a part of independent colleges have cultivated some inter-disciplinary talents, these inter-disciplinary talents have greatly limited knowledge and capacity, and their "interdisciplinary" is the single superposition of some similar disciplines and professional knowledge. "A sudden glimpse of hope appears in the dark mist of bewilderment", independent colleges are suddenly enlightened with the appearance of MOOC. It seems that an answer has been found after repeated reforms in education. Although MOOC has achieved great success in cultivating talents, it remains inappropriate if it is simply copied to the classrooms of independent colleges. After all, there is a great difference between independent college classroom and MOOC. If MOOC is simply applied to the independent colleges, the result would be the same as any of the previous reforms in 
education. Therefore, managers of independent colleges must increase research efforts, absorb the advantages of MOOC, integrate it with the classroom of independent colleges, and finally find out a classroom suitable for the characteristics of the independent colleges in order to lay a foundation for independent colleges to cultivate interdisciplinary talents.

\section{MOOC PROVIDES A GUIDELINE FOR THE INDEPENDENT COLLEGES TO IMPROVE THE EFFICIENCY OF TEACHING AND MANAGEMENT}

The convenience of MOOC improves the efficiency of teaching and management. In the course of teaching, the teachers may send all kinds of course information via the Internet, wireless networks, mobile communications and other IT tools that may appear on the terminals of tens of thousands of learners in an instant. By reading terminal, the learner will be able to master the course information. Thus, transfer of knowledge would have to be instantaneous between teachers and students, and among learners. Moreover, by means of Internet technology and video, MOOC can turn the contents in the previous classrooms for several hours into the information of a few minutes, and this information is more detailed, meticulous and lifelike. It is more convenient, fast and easy for the learners to learn. In addition, the memory retention time is also longer. The convenience and fastness is out of the reach of paper media. In the course of teaching taking paper media as carriers, completion of the classroom requires not only a lot of manpower and resources but also a lot of time, coupled with relatively small curriculum capacity and less teaching methods, it is naturally difficult to arouse the interest of the learner.

After MOOC appears, online registrants are as many as tens of thousands, hundreds of thousands, even millions, tens of millions. Meantime, its course category is also gradually increased. It is quite difficult and unthinkable to use the traditional teaching and management methods to manage so many learners and courses. However, in designing MOOC courses, learners choose the courses through the Internet, teaching managers can quickly summarize course requirements of learners through modern information technology and quickly generate curriculum to facilitate the learners to learn. Meanwhile, teachers read the curriculum over the network and arrange their own courses based on the curriculum, or quickly pass their own views on the course arrangement to teaching management department to help them complete the adjustment of the curriculum. The learner can choose their own courses by reading curriculum and learn when they have enough time. Nonetheless, in the era with the carrier of paper media, it takes several weeks or longer to complete such a large work, also a long time to adjust if any of the links goes wrong.

As traditional institutions of higher learning, both teaching and management of the independent colleges are based on the papers. Despite a considerable number of independent colleges have begun to use modern information technology for the paperless office, the idea of teaching management still remains in the traditional paper-based era, which is bound to have influence on the efficiency of teaching and management. In this case, the absorption of MOOC's way of teaching and management can effectively improve the efficiency of teaching and management of independent colleges.

\section{MOOC PROVIDES A GUIDELINE FOR THE INDEPENDENT COLLEGES TO CHANGE CLASSROOM TEACHING PARADIGM}

MOOC fully demonstrates the essence of classroom teaching, turns teacher basis totally to leaner basis. Teaching and learning itself is a contradictory unity in which the purpose of teachers teaching is to meet the learning of learners. Over the years, we have been carrying out various forms of education reform. However, no matter what kind of reform in education is made, the teaching mode of a teacher in the class is not changed fundamentally. A teacher is still the one who dominates the class, and the dominant position of learners still has not been demonstrated. While MOOC pays special attention to the teacher-student interaction and learning experience of learners, truly restitutes the essence of "learning" of learners to the class, and turns static knowledge imparting into smart education. In the classroom of MOOC, the teacher is no longer the one who teaches or explains but inspires and encourages the students. The spoon-feeding passive learning has passed out of existence, replaced by a new learner-centered educational method. Thus, MOOC is transformed to an aggregation for learners to experience, comprehend, interpret and exchange, and this will certainly make the classroom fasten on "learning".

For teachers and learners, any learning theory courses are extremely boring. Teachers need to exert great efforts in teaching, while the learners need to painstakingly learn. Even so, sometimes it is difficult to achieve the purpose. The MOOC has achieved a perfect unity of theory and interestingness. To avoid boring theoretical knowledge annoying the learners, teachers may divide the MOOC courses. A 45min class may be divided into several "mini classes" of 10min or more. A variety of small questions will be designed in the class. The learners are allowed to continue to learn after getting correct answers. Thus, the boring classroom theory becomes passing through checkpoints full of fun, attracting every learner. Advanced learning is an important mode of MOOC learning which not only enables learners themselves to control the learning progress but also detection and diagnosis in a timely manner. Such setting mode of course arouses the interest of learners and addicts part of the learners who will participate in MOOC learning once they have time. In the learning process, even if the learners encounter with difficult questions, they will be solved by the teachers or other learners after putting on the learning platform, helping the learners to pass through.

On the learning platform of MOOC, learners may comment on any teachers. MOOC faces to the learners all over the world who appear on the MOOC platform in a virtual mode totally. The teachers may communicate with students with an online moniker or real name to avoid the embarrassment of a student commenting on a teacher. MOOC is guided by providing services to the learners who 
can comment on the teachers anytime anywhere, or even give up the learning of some courses not subject to any penalty.

This approach is impossible for any independent colleges. Even through the learners may comment on the teachers casually, not participating in the classroom of the learners is not allowed. The learners do not have any right of not learning in class. That is to say, in the traditional learning process of independent colleges, once they gave set some courses, the learners must complete the learning of these courses unconditionally. Some institutions even take the number of learners participating in the class as the evaluation criterion. Under the circumstances, learners must complete required courses of independent colleges step by step, otherwise before learners is the difficulty of being unable to get a diploma.

At present, most of the independent colleges have traditional classroom teaching paradigm under which the teachers control the classroom totally and learners are not allowed to raise any objection. The learners can only learn passively as designed by the teachers. The nature of liberal learning of learners is totally killed. Depending on the Internet technology, MOOC has no limitations on time and space, has low cost. Besides, the courses are infinitely repeated, so students can learn through their own needs and interests, and may participate in any courses of any university at any time. The perfect classroom teaching paradigm created in this way by MOOC by all means not only fully mobilizes the initiative of learners, turning "make me to learn" into "I want to learn" and truly reflecting the right to speak of the learners in the classroom, but also endows the students a right to comment on any teachers and classroom to totally realize the nature of the learners, providing a guideline for the independent colleges to create a perfect classroom teaching paradigm.

\section{MOOC PROVIDES A GUIDELINE FOR THE INDEPENDENT COLLEGES TO OPEN UP INDIVIDUALIZED EDUCATION}

With the growing competition in the society, academic education is no longer the only choice for people. More people begin to combine the academic with non-academic education, choose individualized education suitable for their own development to continuously increase their own knowledge, improve their skills and strive to create themselves as comprehensive talents. Through the information technology, MOOC designs all kinds of individualized services for the learners, creates excellent courses suitable for all kinds of people, and carries on and develops social attributes, continues to promote learners to learning to improve learning outcomes. To motivate learners and help them realize their own values, MOOC also provides employment services for the learners, combining the enterprises with MOOC, provides learners with businessrelated courses, and match them with corresponding enterprises or companies according to the learners' interests, knowledge and skills. Learners can learn according to their own interests, and find out enterprises or companies suitable for their own development through MOOC, and finally realize their own values by participating in business or the company's production.

Opening up individualized education and cultivating comprehensive talents are important tasks of the independent colleges. However, in the course of education and teaching, although the independent colleges have tried a variety of personnel training methods, the outcomes are not satisfied. To complete the task of cultivating comprehensive talents, the independent colleges can fully transplant the individualized teaching approach of MOOC, and then complete their task of teaching.

In short, as public private secondary schools, independent colleges are still in a weak position compared with other institutions of higher learning. In this case, only carefully analyzing the gap, absorbing the essence of MOOC can the independent colleges continuously enhance their own level and complete the task of education and teaching.

\section{REFERENCES}

[1] Xu Suyan, College Curriculum and Teaching Reform under the Development of Online Education [J]. Higher Education Exploration, 2014, 04: 97-102.

[2] Wang Xin, Path Choice of College Foreign Language Teaching Mode in the Sight of MOOC[J]. Heilongjiang Researches on Higher Education, 2014, 08:157-159.

[3] Wisdom Tree, East-west university course sharing alliance is formally established to promote the reform of teaching mode with information technology [EB/OL].
[E http://www.wemooc.edu.cn/union/pages/notice/notice02.jsp, 201304-27.

[4] Kolowich S.American Council on Education Recommends 5 MOOCs for Credit[J]. The chronicle of Higher Education, 2013-02-07(6).

[5] Zhang Zhiyuan, Influence of MOOCs Development on Higher Education in China and its Countermeasures [J]. Hebei Normal University Journal (Educational Science Edition), 2014, 16(02):116121. 